\title{
Use of Mineral Reference Standards in EPMA: Instrumental Calibration, Standards Comparison, and Quality Control
}

\author{
P. K. Carpenter ${ }^{1}$ and E.P. Vicenzi ${ }^{2}$ \\ ${ }^{1 .}$ Earth and Planetary Sciences, Washington University, St. Louis, MO, USA \\ 2. Smithsonian Institution, Suitland, MD, USA
}

In electron-probe microanalysis (EPMA), concentration $C$ is calculated from the $k$ ratio of measured Xray intensity emitted from a sample relative to a primary standard where $k=(P-B)^{s m p} /(P-B)^{s t d}$, and corrected for matrix effects via $C=k * Z A F$. The accuracy of this measurement depends on the instrumental calibration, $k$ measurement from background corrected peak intensity on samples and standards, and conversion to concentration units by the correction algorithm. For standards this equation is used to calculate $k_{\text {calc }}$ from known $C$ using a given correction algorithm, and for samples the measured $k_{\text {meas }}$ is used to calculate $C$ using the same algorithm. The $k_{\text {meas }}$ depends on all aspects of measurement including spectrometer alignment and the calibration intensity measurement, whereas $k_{\text {calc }}$ depends on all aspects of correction including the standard composition and the correction algorithm. The ratio $k_{\text {meas }} / k_{\text {calc }}$ should be unity if measurement and calculation are error-free. Measurements on a suite of microprobe standards using this unbiased comparison has been used to identify errors in alignment of wavelength-dispersive spectrometers (WDS), standard compositions, background determination, and to demonstrate the internal consistency of a suite of standards and accuracy of correction algorithms [1]. A diagnostic plot of $k_{\text {meas }} / k_{\text {calc }}$ vs. concentration is the multielement equivalent of the error histogram historically used to evaluate binary element $k$ data (Fig. 1).

Two general approaches are made in use of microanalysis standards for EPMA. First, high concentration standards are used for primary calibration so that high X-ray intensity and therefore high cps/wt. \% are established for a given element. The high $\mathrm{P} / \mathrm{B}$ measured on the calibration standard results in high measurement precision and detection limit for measurement on samples. Analytical accuracy is demonstrated by analysis of Smithsonian Microbeam Standards as secondary standards [2-3]. This approach provides a wide concentration range for which the calibration can be used, but depends on significant projection in the ZAF correction. A second approach uses primary calibration standards matched to the samples being analyzed, which minimizes the ZAF projection in correction, and reduces the chance of k-ratio measurement error as the element inventory is the same in standard vs. sample, but limits the applicability of the calibration especially to samples having a higher concentration of a given element.

Kakanui hornblende $(\mathrm{KH})$ is an especially important EPMA standard as it can be used as both a primary and secondary calibration reference for routine analysis of minerals. Each silicate microprobe run at Washington University includes $\mathrm{KH}$ as a secondary standard for both short and long-term quality control. Analyses of KH reveal per-spectrometer and/or per-element standardization issues using a single measurement and thus provide immediate confirmation of the calibration validity. Inspection using backscattered-electron (BSE) imaging reveals that $\mathrm{KH}$ contains sub-micron and larger inclusions (e.g., titanomagnetite, glass), and also wispy features that represent subgrain boundaries. The nm-sized inclusions are pervasive but variable in number, and warrant the use of a $20 \mu \mathrm{m}$ beam diameter which effectively eliminates their contribution to the analysis. Fig. 2A shows a 5 year summary of 
measurements for $\mathrm{Ti}$ on $\mathrm{KH}$ using a WDS with sealed Xe detector, emphasizing the excellent reproducibility of the measurement procedure using a defocused beam.

We report here ongoing studies that have utilized $\mathrm{KH}$ for a comparison of intragrain and intergrain homogeneity [4]. EPMA analyses were made of individual grains vs. single grains with different inclusion densities, as well as glass and mineral inclusions and wispy regions in the grains. These data are compared with the wet chemistry data for the bulk separate in Table 1. One can conclude that by using a defocused beam there is very good agreement between EPMA and wet chemistry data even for grains that have a higher abundance of nm-sized inclusions. These features have not been observed in the distribution size fraction, but still may be present as discrete grains.

In summary, EPMA standards are important for primary and secondary calibration, and additionally for instrumental setup and quality control monitoring.

\section{References:}

[1] PK Carpenter, Microsc. Microanal. 17(S2) (2011).

[2] Jarosewich et al, Geostandards Newsletter 4(1) (1980), p. 43.

[3] Jarosewich, et al, Smithsonian Contrib. Earth Sci, 22:53-67 (1979).

[4] EP Vicenzi and TR Rose, Microsc. Microanal. 14(S2) (2008).

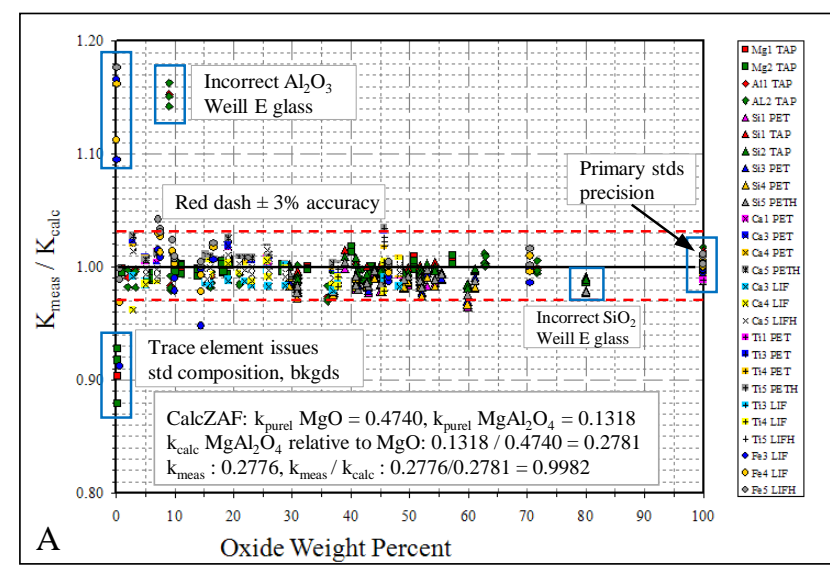

\begin{tabular}{|c|c|c|c|c|c|c|}
\hline B & MgO & $\mathrm{Al} 2 \mathrm{O} 3$ & $\mathrm{SiO} 2$ & $\mathrm{CaO}$ & $\mathrm{TiO}_{2}$ & $\begin{array}{c}\mathrm{FeO}^{*} \text { or } \\
\mathrm{Fe} 2 \mathrm{O3}\end{array}$ \\
\hline Alaska Anorthite & & 36.03 & 44.00 & 19.09 & & \\
\hline Boyd Olivine & 51.63 & & $\begin{array}{r}40.80 \\
40.85\end{array}$ & & & 7.17 \\
\hline Ilmen Mtns Ilmenite & 0.31 & & & & 45.70 & 46.54 \\
\hline K411 Glass & 14.67 & 0.10 & 54.30 & 15.47 & & 14.42 \\
\hline $\begin{array}{l}\text { K412 Glass } \\
\text { Kyanite P236 }\end{array}$ & 19.33 & $\begin{array}{l}9.27 \\
6291\end{array}$ & 45.35 & 15.25 & & 9.96 \\
\hline $\begin{array}{l}\text { Kyanite P236 } \\
\text { Natural Bridge Diopside }\end{array}$ & 18.31 & 0.06 & 55.40 & 25.78 & 0.01 & 0.26 \\
\hline ORNL, RDS Fayalite & & & 29.49 & & & 70.51 \\
\hline San Carlos Olivine & 49.42 & & 40.81 & & & 9.55 \\
\hline Shankland Forsterite & 57.30 & & 42.70 & & & \\
\hline Springwater Olivine & 43.58 & & 38.95 & & & 16.62 \\
\hline Taylor Kyanite & 0.00 & 62.70 & 37.00 & & & 0.16 \\
\hline Taylor Olivine & 50.78 & & 41.15 & & & 7.62 \\
\hline Taylor Sphene & & 1.36 & 30.83 & 28.82 & 37.80 & 0.66 \\
\hline Taylor Spinel & 28.34 & 71.66 & & & & \\
\hline Weill A & 11.05 & 16.07 & 49.72 & 23.15 & & \\
\hline Weill B & 13.99 & 16.05 & 48.99 & 20.97 & & \\
\hline Weill D & 17.97 & 20.96 & 45.07 & 16.00 & & \\
\hline Weill $\mathrm{E}^{*}$ & 6.00 & 8.99 & 79.97 & 5.04 & & \\
\hline Weill Enstatite Glass & 40.15 & 0.00 & 59.85 & & & \\
\hline Weill F & 10.07 & 30.93 & 52.06 & 6.94 & & \\
\hline Weill G & 32.69 & 3.31 & 61.12 & 2.89 & & \\
\hline Weill $\mathbf{H}$ & 5.22 & 41.90 & 30.91 & 21.97 & & \\
\hline Weill I & 19.03 & 2.01 & 52.95 & 26.01 & & \\
\hline Weill J & 1.01 & 19.02 & 42.98 & 36.99 & & \\
\hline
\end{tabular}

Figure 1. A: Ratio $\mathrm{k}_{\text {meas }} / \mathrm{k}_{\text {calc }}$ for standards listed in Fig. $\mathrm{B}$, ( $\mathrm{k}_{\text {calc }}$ using Armstrong $\Phi(\rho z)$ and Henke macs), with important features regarding precision, accuracy, and standard compositions. B: List of accepted standard compositions used for calibration comparison program.

\begin{tabular}{|c|c|c|c|c|c|c|c|c|c|c|c|c|}
\hline Kakanui hornblende long-term Ti measurements: Spec 5 Ti LiFH Xe & $B$ & Table 1 & $\mathrm{Na}$ & $\mathrm{Mg}$ & Al & $\mathrm{Si}$ & $\mathbf{K}$ & $\mathrm{Ca}$ & $\mathrm{Fe}$ & $\mathrm{Ti}$ & o & Total \\
\hline 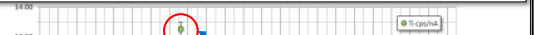 & & Wet chemistry & 1.93 & 7.72 & 7.87 & 18.87 & 1.70 & 7.36 & 8.49 & 2.83 & 43.06 & 99.69 \\
\hline & & $\begin{array}{l}42 \text { grain average } \\
\mathrm{n}=3 \text { for each grain }\end{array}$ & 1.99 & 7.66 & 7.69 & 18.98 & 1.78 & 7.30 & 8.26 & 2.93 & 42.65 & 99.39 \\
\hline $\begin{array}{l}\text { Ti sensitive indicator of ilmenite }\left(\mathrm{FeTiO}_{3}\right) \text { inclusions } \\
\text { Probe run which incorrectly used a focused beam on } \mathrm{KH}\end{array}$ & & "Clean" grain, $\mathrm{n}=264$ & 2.00 & 7.62 & 7.64 & 18.89 & 1.78 & 7.30 & 8.25 & 2.93 & 42.48 & 99.05 \\
\hline 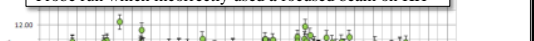 & & $\begin{array}{l}\text { Heterogeneous grain } \\
\mathrm{n}=243\end{array}$ & 1.94 & 7.74 & 7.57 & 18.72 & 1.76 & 7.32 & 8.27 & 2.96 & 42.31 & 98.74 \\
\hline 产" & & Dark BSE, $\mathrm{n}=4$ & 1.51 & 9.02 & 7.58 & 19.09 & 2.06 & 8.05 & 5.71 & 3.36 & 43.31 & 99.82 \\
\hline 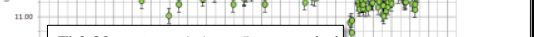 & & Intermediate BSE, $\mathrm{n}=2$ & 1.78 & 8.40 & 7.32 & 19.06 & 1.62 & 7.86 & 7.17 & 3.19 & 42.88 & 99.45 \\
\hline Ti $2.83 \mathrm{wt} \%, \mathrm{cps} / \mathrm{nA}$ vs. 5 year period & & Glass inclusions $\mathrm{n}=2$ & 2.01 & 0.18 & 11.59 & 27.41 & 3.31 & 1.87 & 3.37 & 0.36 & 45.84 & 96.12 \\
\hline 2007 to 2012 & & Titanomagnetite, $\mathrm{n}=5$ & 0.03 & 3.93 & 4.58 & 0.12 & 0.04 & 0.21 & 51.75 & 8.14 & 32.18 & 101.25 \\
\hline$\longrightarrow$ & & $\begin{array}{l}\text { Concentrations in element we } \\
\text { Wet chemistry data of Jarosew }\end{array}$ & $\begin{array}{l}\text { th per } \\
\text { thet }\end{array}$ & & . & $\begin{array}{l}\text { stoich } \\
\text { ende }\end{array}$ & & & & & & \\
\hline 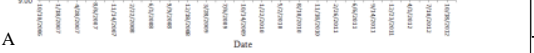 & Kakanui hornblende BSE 490X & $\begin{array}{l}\text { EAMA data: } 1 \text { 15kVV,25nA, Prol } \\
\text { (Al), Madagascar orthoclase } \\
\text { macs. Backgrounds determine }\end{array}$ & K), Gates & & & & $\% \mathrm{H} . \mathrm{C}$ & centra & s for $\mathrm{Mnn}$ & $\begin{array}{l}\text { trong } \Phi(f) \\
t \text { tisted. }\end{array}$ & & trath \\
\hline
\end{tabular}

Figure 2. A: Long-term Ti K $\alpha$ intensity data over 5 year period. B: BSE images of KH, heterogeneous grain with large and small inclusions. Table 1: Comparison of wet chemistry and EPMA data. 